\title{
Incidence of T-strain mycoplasmas in male and female subjects attending a venereal diseases clinic
}

\author{
N. P. MARKHAM, J. G. MARKHAM, AND E. R. SMITH \\ Laboratory Services Department, Dunedin Hospital, and the Department of Microbiology, Otago University \\ Medical School, Dunedin, New Zealand
}

Shepard (1954) isolated mycoplasmas, from the human urogenital tract, which grew as 'tiny' colonies on agar medium and have subsequently been referred to as T-strain mycoplasmas or T-mycoplasmas.

Shepard (1956) noted that T-strain mycoplasmas were present in a high proportion of patients with non-gonococcal urethritis, and it was suggested that the organisms played a part in the aetiology of that disease. Because of the increasing prevalence of non-gonococcal urethritis, this hypothesis has since been investigated in several studies, in most of which the incidence of $T$-strain mycoplasmas was found to be higher in groups of men suffering from nongonococcal urethritis than in comparable but symptom-free control groups.

Non-gonococcal urethritis has increased in New Zealand as in other countries, and for this reason it was decided to assess the incidence of T-strain mycoplasmas in groups of men and women reporting at the venereal diseases clinic of the Dunedin Hospital and in some other subjects.

\section{PATIENTS AND SUBJECTS EXAMINED}

All were assigned to the groups shown below and in Table I which records the age distribution within the groups. There were more females than males in the 15 to 20-year age group. The majority of men and

Received for publication October 6, 1971 women attending the clinic form a homogeneous socioeconomic group; attendance at the clinic, when symptoms or conscience indicate, is part of their way of life and for this reason they are unlikely to have received treatment before reporting.

\section{Males}

(1) Patients with gonorrhoea (52)

All had acute urethritis with exudate positive for Neisseria gonorrhoeae.

(2) Patients with non-gonococcal urethritis (115)

In half, urethral discharge, usually accompanied by dysuria, occurred between 1 and 7 days after the last sexual contact and in the remainder between 8 and 28 days. $N$. gonorrhoeae were not seen in a direct smear or isolated by culture and antibiotics had not been taken up to the time of the first examination. Ten patients had had two episodes of non-gonococcal urethritis, the second after sexual contact with another partner.

(3) Symptom-free subjects with a history of recent sexual contact (29)

These men thought that they might have contracted venereal disease and wished to be reassured.

(4) Patients who had had non-gonococcal urethritis and had completed a course of tetracycline (17)

Tetracycline had been given before culture for $\mathrm{T}$-strain mycoplasmas was made and when symptoms had been relieved or had disappeared.

TABLE I Groups of male and female subjects, by age

\begin{tabular}{|c|c|c|c|c|c|}
\hline \multirow{2}{*}{ Sex } & \multirow{2}{*}{ Group } & \multirow{2}{*}{$\begin{array}{l}\text { No. } \\
\text { examined }\end{array}$} & \multicolumn{3}{|c|}{ Age (yrs) } \\
\hline & & & $\begin{array}{l}15-20 \\
(\%)\end{array}$ & $\begin{array}{l}21-25 \\
(\%)\end{array}$ & $\begin{array}{l}\text { Over } 25 \\
(\%)\end{array}$ \\
\hline Male & $\begin{array}{l}\text { Gonorohoea } \\
\text { Non-gonococcal urethritis } \\
\text { Casual contact-no symptoms } \\
\text { Non-gonococcal urethritis-after tetracycline treatment } \\
\text { No symptoms-no casual contact }\end{array}$ & $\begin{array}{r}52 \\
115 \\
29 \\
17 \\
27\end{array}$ & $\begin{array}{l}42 \\
58 \\
59 \\
47 \\
26\end{array}$ & $\begin{array}{l}44 \\
32 \\
31 \\
41 \\
15\end{array}$ & $\begin{array}{l}14 \\
10 \\
10 \\
12 \\
59\end{array}$ \\
\hline Female & $\begin{array}{l}\text { Gonorrhoea } \\
\text { Casual contact-symptoms } \\
\text { Casual contact-no symptoms }\end{array}$ & $\begin{array}{l}41 \\
33 \\
58\end{array}$ & $\begin{array}{l}64 \\
82 \\
90\end{array}$ & $\begin{array}{c}29 \\
15 \\
8\end{array}$ & $\begin{array}{l}7 \\
3 \\
2\end{array}$ \\
\hline
\end{tabular}


(5) Subjects without a history of casual sexual contact or urethritis (27)

This group included volunteers, patients with skin disorders and patients attending hospital for cystoscopy after bladder operations.

The age and sexual habits of members of this group differed from those of the first four groups.

\section{Females}

(1) Patients with gonorrhoea (41)

The diagnosis was made by isolating $N$. gonorrhoeae from cervical or urethral exudate.

(2) Patients with symptoms after recent sexual contact (33) All had vaginal discharge from which $N$. gonorrhoeae was not isolated.

(3) Subjects without symptoms after recent sexual contact (58) These subjects did not admit to abnormal discharge and cultures were negative for $N$. gonorrhoeae.

\section{METHODS}

\section{Collection of specimens for mycoplasma culture}

Specimens were collected with a loop by scraping the distal $2 \mathrm{~cm}$. of the urethra in males or the upper part of the vagina in females.

\section{Cultural procedure}

For the isolation of $N$. gonorrhoeae, Thayer Martin medium was seeded at the time of collection of specimens.

The isolation method for $\mathrm{T}$-strain mycoplasmas was essentially that recommended by Taylor-Robinson, Addey, and Goodwin (1969). In addition to the distinctive tiny colony formation, these organisms are unique amongst the Mycoplasmatales in containing urease and requiring urea as a metabolite (Shepard and Lunceford, 1967; Purcell, Taylor-Robinson, Wong, and Chanock, 1966). $T$-strain mycoplasmas can be detected in clinical material by using the urease colour test medium U-9 as described by Shepard and Lunceford (1970), and in the present study this medium was used but modified to the extent that pig serum replaced horse serum and the urea content was increased to 0.1 per cent. to compensate for the lower urea content of pig serum. The modified U-9 medium contained tryptic digest broth powder Difco No. 097701-8 0.75 g.; sodium chloride $0.5 \mathrm{~g}$.; monobasic potassium phosphate $0.02 \mathrm{~g}$; deionized water $100 \mathrm{ml}$. as the basal broth to which was added 4 per cent. unheated pig serum; 0.001 per cent. phenol red and 1,000 i.u. $/ \mathrm{ml}$. penicillin G-final pH 6.0.

The agar medium for colony identification was based on the A2 agar medium of Shepard (1967) and the medium used by Taylor-Robinson and others (1969). It consisted of trypticase-soy broth; pig serum 20 per cent.; yeast extract 1 per cent.; urea $0 \cdot 1$ per cent.; penicillin G 1,000 i.u./ml.; ion-agar No. 21 per cent. and phenol red 0.001 per cent.-final $\mathrm{pH} 6 \cdot 0$.

After about $14 \mathrm{hrs}$ incubation at $36^{\circ} \mathrm{C}$., following inoculation, the production of ammonia by $\mathrm{T}$-strain mycoplasmas growing in the urea broth changed the colour from yellow to pink. At this time, subculture was made on the agar medium which was examined after 1,2 , and 3 days' incubation in 8 per cent. $\mathrm{CO}_{2}$ in air for change of colour from yellow to red. The plates were searched with the low power lens ( 100$)$ of the microscope for the presence of colonies. The presence of a very few colonies could produce a pink colour in the medium but occasional strains failed to do this. In the first urea broth culture, urease in epithelial cells may produce a false positive result (Taylor-Robinson and others, 1969) and for this reason a positive test for T-strain mycoplasmas was accepted only if a colour change occurred in the second broth subculture in the absence of turbidity indicating bacterial or fungal contamination.

\section{Results}

\section{Isolation of T-strain mycoplasmas}

Of the 372 initial urea broth cultures, 262 gave a positive colour result in the 1:10 dilution subcultures, and 236 (90 per cent.) of these produced typical $\mathrm{T}$-strain colonies on agar subcultures.

Incidence of T-strain mycoplasmas in various groups of subjects

MALES

The incidence (Table II, overleaf) was nearly equal and highest in patients suffering from gonorrhoea and non-gonococcal urethritis (83 and 85 per cent., respectively), and was significantly greater than the incidence found in the symptom-free group ( 52 per cent.) which had the same age distribution and sexual habits. Only one isolation ( 6 per cent.) was made from the seventeen non-gonococcal urethritis patients who had had recent tetracycline therapy. No Tstrains were found in the group of symptom-free subjects who did not engage in casual sexual contact, but the age and medical histories of these precluded comparison with the other groups.

\section{FEMALES}

The incidence of T-strain mycoplasmas in the three female groups is shown in Table II. Isolation rates were highest and nearly equal in patients with gonorrhoea and with non-gonococcal vaginal discharge ( 85 and 82 per cent., respectively) but only slightly lower in the symptom-free group (74 per cent.). The differences were not significant.

Association of T-strain mycoplasmas with post-gonorrhoeal urethritis in males.

Patients with gonorrhoea are treated initially with penicillin. Two (14 per cent.) of fourteen patients with gonorrhoea, but not carriers of $\mathrm{T}$-strains, returned with post-gonorrhoeal urethritis; both were cured by subsequent tetracycline treatment. Sixteen (41 per cent.) of 38 patients who carried T-strains developed post-gonorrhoeal urethritis; four were 
TABLE II Incidence of T-strain mycoplasmas in various groups, by sex

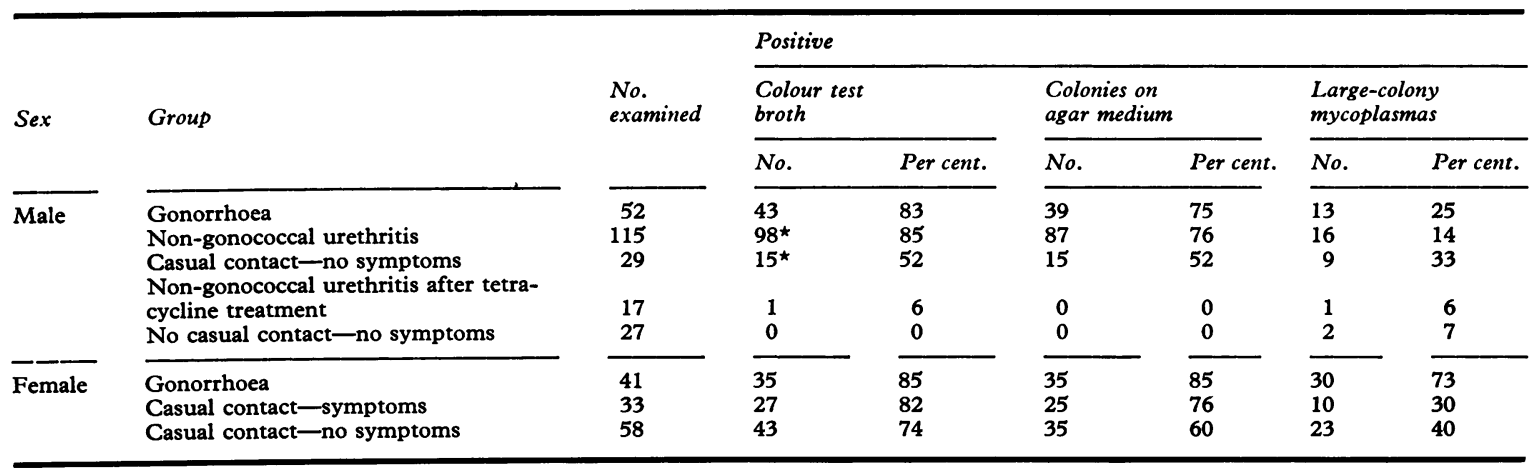

$\star$ Difference highly significant $P<0.001$

cured after a second course of penicillin and twelve with tetracycline therapy. Thus post-gonorrhoeal urethritis occurred three times more frequently in those males with gonorrhoea who were also carriers of T-strain mycoplasmas.

\section{Non-gonococcal urethritis and tetracycline therapy}

It is the practice at the clinic to treat patients with non-gonococcal urethritis with oral tetracycline (500 mg. four times daily for 2 days, then $250 \mathrm{mg}$. four times daily for 2 days). Reference has already been made (Table II) to isolation of a $T$-strain from one of seventeen patients who were first investigated for $\mathrm{T}$-strain mycoplasmas after receiving tetracycline.

A further 23 patients with non-gonococcal urethritis were investigated before and after tetracycline treatment (Table III). Fourteen were relieved of symptoms and $T$-strains disappeared after one course of tetracyline. In five patients, two courses were required and, in four patients, two courses of tetracycline and a final course of erythromycin had to be given. Failure to cure symptoms was associated with an observed persistence of $\mathrm{T}$-strain mycoplasmas.

TABLE III T-strain mycoplasmas and tetracycline therapy in non-gonococcal urethritis

\begin{tabular}{|c|c|c|c|}
\hline \multirow{3}{*}{$\begin{array}{l}\text { No of patients } \\
\text { followed }\end{array}$} & \multicolumn{3}{|c|}{ Symptoms relieved by } \\
\hline & \multicolumn{2}{|l|}{ Tetracycline } & \multirow{2}{*}{$\begin{array}{l}\text { Tetracycline } \\
(2 \text { courses }) \\
\text { plus } \\
\text { erythromycin }\end{array}$} \\
\hline & One course & Two courses & \\
\hline 23 & $14^{\star}$ & $5 t$ & $4 \dagger$ \\
\hline
\end{tabular}

Large-colony mycoplasmas

Large-colony mycoplasmas with a typical colony morphology and presumed to be Mycoplasma hominis were observed, frequently associated with $\mathrm{T}$-strain colonies on the agar medium. The number of isolates is shown in Table II. The incidence was highest in the female groups, especially in girls with gonorrhoea. In the male groups, large-colony mycoplasmas were isolated less frequently from patients with gonorrhoea and non-gonococcal urethritis than from the symptom-free sexually active males.

\section{Contacts of men with non-gonococcal urethritis}

The last female contacts of 31 males with nongonococcal urethritis were examined (Table IV). In 28 partnerships, both male and female were carriers of $\mathrm{T}$-strain mycoplasmas; in one the male was negative and the female positive and in two pairs both partners were negative.

TABLE IV Incidence of $T$-strain mycoplasmas and large colony mycoplasmas (M. hominis) in 31 male and female partners

\begin{tabular}{|c|c|c|c|c|}
\hline \multirow{2}{*}{ Mycoplasmas } & \multicolumn{2}{|l|}{ Male + } & \multicolumn{2}{|l|}{ Male - } \\
\hline & Female + & Female - & Female + & Female - \\
\hline $\begin{array}{l}\text { T-strain } \\
\text { Large-colony }\end{array}$ & $\begin{array}{r}28 \\
4\end{array}$ & $\begin{array}{l}0 \\
3\end{array}$ & $\begin{array}{r}1 \\
13\end{array}$ & $\begin{array}{r}2 \\
11\end{array}$ \\
\hline
\end{tabular}

Large-colony strains were shared between partners much less frequently than were $T$-strain mycoplasmas.

\section{Discussion}

Jansson, Lassus, Stubb, and Tuuri (1971), who listed most of the surveys of the incidence of $T$-strain mycoplasmas in groups of patients with non-gonococcal urethritis and in 'control' groups, concluded 
that the evidence for the possible pathogenic role of these organisms is equivocal. Hare, Dunlop, and Taylor-Robinson (1969) were unable to find a causal relationship between $\mathrm{T}$-strain mycoplasmas and post-gonorrhoeal urethritis, and Csonka, Williams, and Corse (1966) and Holmes, Johnson, Floyd, and Kvale (1967) produced contrary evidence although the last-named workers did not identify the precise nature of the mycoplasmas isolated.

The incidence of $\mathrm{T}$-strain mycoplasmas has been studied in various groups of female subjects (Csonka and others, 1966; Archer, 1968). These organisms were commonly found in sexually mature, healthy women (over 50 per cent.), were absent or rarely found in nuns and in young girls up to the age of 18 , and were most common in women suffering from gonorrhoea and in promiscuous girls (Solomon, Sompolinsky, Caspi, and Alkan, 1970).

A comparison of published estimates of the incidence of $T$-strain mycoplasmas is made difficult by variations in method of collection of specimens, use or non-use of transport medium and use of culture media which have often included thallium acetate, a substance known to be inhibitory to T-strain mycoplasmas (Shepard, 1967). Furthermore, it is not always clear if the possibility of previous treatment with tetracycline or erythomycin has been excluded.

The introduction of the urease test broth has to a large extent simplified the procedure of isolating T-strain mycoplasmas. Shepard and Lunceford (1970) found a 98.1 per cent. agreement between the urease reaction in U-9 urease colour test medium and positive results in a standard primary agar culture; the disagreeing false positive reactions were recognized visually as being due to bacterial contamination. Taylor-Robinson and others (1969) regarded it as the most sensitive, quick, and simple method for the isolation of T-strain mycoplasmas. We have identified $\mathrm{T}$-strain colonies from 90 per cent. of positive primary broth cultures subcultured on agar medium, and failure to do so in the remaining 10 per cent. was due to unavoidable delays in subculturing, thus exceeding the critical time after which the accumulation of ammonia formed by the T-strains impairs the viability of the organism (Manchee and Taylor-Robinson, 1969).

By the use of the colour test medium it was found that most of the women attending the venereal diseases clinic carried $\mathrm{T}$-strain mycoplasmas in the vagina.

Half of the symptom-free men who had had sexual contact with these or like women were carriers of this organism and the carriage rate was significantly higher in male contacts who had developed gonococcal or non-gonococcal urethritis. Some men who had frequent sexual intercourse with a single female were carriers of $T$-strain mycoplasmas but remained symptom-free until they changed to a second partner when ' $T$-strain mycoplasma positive' non-gonococcal urethritis developed.

It is known that several serological types of $\mathrm{T}$ strain mycoplasmas exist (Purcell, Chanock, and Taylor-Robinson, 1969) and it is possible that not all types have equal pathogenicity and that host resistance to one type may not be effective against another type. The serological studies of Jansson and others (1971) using direct haemagglutination techniques give some support to these possibilities.

In addition to the higher incidence of $T$-strain mycoplasmas in males with urethritis, our observations that the remission of symptoms after tetracycline or erythromycin therapy was accompanied by the disappearance of $\mathrm{T}$-strain mycoplasmas, and the increased incidence of post-gonorrhoeal urethritis in ' $\mathrm{T}$-strain positive' gonorrhoea, support the contention that $\mathrm{T}$-strain mycoplasmas are an aetiological agent in post-gonorrhoeal and non-gonococcal urethritis.

\section{Summary}

The incidence of $T$-mycoplasmas in males suffering from gonorrhoea (83 per cent.) and from non-gonococcal urethritis ( 85 per cent.) was significantly higher than the incidence in symptom-free males ( 52 per cent.) who followed the same patterns of sexual activity. No isolations were made from a group of 29 men who did not have urethritis or indulge in casual sexual contacts.

Males with gonorrhoeal infection associated with T-mycoplasmas developed post-gonorrhoeal urethritis more frequently than those from whom T-mycoplasmas were not isolated (42 and 14 per cent., respectively).

Tetracycline and erythromycin cured symptoms of non-gonococcal urethritis and eliminated T-mycoplasmas from urethral secretions.

The female partners of men with ' $T$-mycoplasma positive' non-gonococcal urethritis also carried the organism.

Large-colony mycoplasmas were isolated most frequently in the female groups and the incidence was highest in women with gonorrhoea. Sexually active, symptom-free men had a higher incidence than men with gonorrhoea and non-gonococcal urethritis.

The authors thank Dr H. C. W. Stringer, whose encouragement made this study possible, and acknowledge the help given by $\mathrm{Mr}$ E. O. Dawson and $\mathrm{Mr}$ M. E. Shackleton. They are grateful for the constructive criticism given by Prof. J. A. R. Miles and for the technical assistance of Mrs K. A. Warburton. 


\section{References}

ARCHER, J. F. (1968) Brit. F. vener. Dis., 44, 232

CSONKa, G. W., Williams, R. E. O., and Corse, J. (1966) Lancet, 1, 1292

Hare, M. J., Dunlop, E. M. C., and Taylor-Robinson, D. (1969) Brit. F. vneer. Dis., 45, 282

Holmes, K. K., Johnson, D. W., Floyd, T. M., and Kvale, P. A. (1967) F. Amer. med. Ass., 202, 467

Jansson, E., LASSUS, A., StuBb, S., and TUURI, S. (1971) Brit. F. vener. Dis., 47, 122

MANCHEE, R. J., and TAYLOR-RoBINSON, D. (1969) $\mathcal{f}$. Bact., 100, 78

PurCell, R. H., Chanock, R. M., and Taylor-Robinson, D. (1969) In 'The Mycoplasmatales and the L-phase of Bacteria', ed. L. Hayflick, p. 221. AppletonCentury-Crofts, New York; North Holland Publishing Co., Amsterdam

-, TAYLOR-Robinson, D., Wong, D. C., and Chanock, R. M. (1966) f. Bact., 92, 6

SHEPARD, M. C. (1954) Amer. F. Syph., 38, 113

- (1956) f. Bact., 71, 362

- (1967) Ann. N.Y. Acad. Sci., 143, 505

- and LUNCEFORD, C. D. (1967) F. Bact., 93, 1513

- (1970) Appl. Microbiol., 20, 539

Solomon, F., Sompolinsky, D., CASPI, E., and AlKan, W. J. (1970) Isreal F. med. Sci., 6, 605

TAYLOR-Robinson, D., AdDEY, JEAN P., and Goodwin, C. S. (1969) Nature (Lond.), 222, 274
Incidence de mycoplasmes de souche $T$. chez les consultants, hommes et femmes, d'une clinique vénéréologique

SOMMAIRE

L'incidence de mycoplasmes $T$. chez des hommes atteints de gonococcie ( 83 pour cent) et d'urétrites non gonococciques ( 85 pour cent) fut significativement plus élevée que che $\mathrm{Z}$ les hommes sans symptômes ( 52 pour cent), ayant les mêmes modes d'activité sexuelle. Il n'en fut pas trouvé dans un groupe de $\mathbf{2 5}$ hommes qui n'avaient pas d'urétrite ou qui avaient des contacts sexuels occasionnels.

Les hommes gonococciques chez lesquels on trouva des mycoplasmes $T$. présentèrent une urétrite post-gonococcique plus fréquemment que ceux chez lesquels il n'en fut pas trouvé (respectivement 42 et 14 pour cent).

La tétracycline et l'érythromycine firent disparaître les symptômes d'urétrite non gonococcique et les mycoplasmes $T$. ne furent plus retrouvés dans les sécrétions urétrales.

Les partenaires féminins des hommes atteints d'urétrite non gonococcique avec présence de mycoplasmes $T$. hébergeaient également cet organisme.

Des mycoplasmes à larges colonies furent isolés plus fréquemment dans les groupes féminins et l'incidence fut plus élevée chez les femmes atteintes de gonococcie. Les hommes sans symptômes, mais sexuellement actifs, en présentèrent davantage que les hommes atteints de gonococcie ou d'urétrite non gonococcique. 